5th International Science Congress \& Exhibition APMAS2015, Lykia, Oludeniz, April 16-19, 2015

\title{
A Novel High Strain Rate Sensitive Rigid Polyurethane Resin Based Syntactic Foam
}

\author{
M. YAZICI* \\ Uludağ University, Engineering Faculty, Automotive Engineering Dept., Tr16059 Bursa, Turkey
}

Syntactic foams are closed cell structured foam materials and present improved properties for lightweight and high performance material requests. They have been widely used in naval, aeronautical, aerospace, civil, industrial, and automotive engineering applications on account of their good acoustical attenuation, excellent strength to weight ratio, vibration isolation, dielectric properties. In this study, a novel high strain rate sensitive syntactic foam was developed. A rigid polyurethane resin was used as a binder material. Glass bubbles were used as an additive for producing cell structure. Elastomeric silicone rubber resin were used to change elastic properties of the foam as an additional binder material. Quasistatic compression properties and high strain rate compression properties were obtained by using Instron Universal Tensile-Compression Machine and Split Hopkinson Pressure Bar experimental setup respectively. The results show that developed foams are low dense and very high strain rate sensitive materials. Consequently, developed foam can be used for the blast, impact or ballistic mitigation purpose as a coating material.

DOI: 10.12693/APhysPolA.129.613

PACS/topics: 62.23.Pq, 61.43.Gt, 61.41.+e, 62.20.--x

\section{Introduction}

Syntactic foams are a class of closed-cell foam which is manufactured by filling a polymeric matrix with hollow spheres called microspheres or micro balloons $[1,2]$. They have been widely used in several engineering applications due to their low moisture absorption, good thermal insulation, and excellent strength to weight ratio, vibration isolation, and low radar cross-section properties [3-5]. As a class of advanced lightweight composites, syntactic foams have been widely employed in more and more engineering applications, e.g., civil, automobile, aeronautical, marine equipment for deep sea operations [6], aircraft components, spacecraft solid rocket booster nose cones fillings, thermal insulation for deep sea pipelines [7-9], core materials of sandwiches [10, 11], and structural components in aerospace industry [12].

There are limited number of the study found in the open literature about polyurethane (PU) based syntactic foams. Pellegrino et al. [13-15] presented that the PU based syntactic foam's strain rate sensitivity was superior to that of solid PU and conventional PU foams of similar density. However, higher content of the bubbles worsen the compression properties owing to an increased amount of defects in the structure of the filled polyurethane [14].

Polyurea is a special type of elastomer which is widely used as a coating material in transportation, pipelines, steel buildings or marine constructions. More recently, polyurea is also considered for the blast or ballistic mitigation because of its strong strain rate dependence and becomes stiffer with increasing loading rate [16-20].

*e-mail: myazici@uludag.edu.tr
In this study, novel high strain rate sensitive PU based syntactic foams with silicone rubber toughening were developed. Quasi-static and high strain rate compression experiments were performed. The results were discussed with respect to glass bubble weight percentage. The results are also compared with the polyurea impact resistive coating material properties obtained from the literature.

\section{Materials and method}

The syntactic foams used in this study were produced by using rigid $\mathrm{PU}$ resin with the incorporation of silicone rubber resin and glass bubbles (GBs). GBs (Fig. 1a) were obtained from 3M Company with the product code A20/1000. The GBs have $0.2 \mathrm{~g} / \mathrm{cm}^{3}$ density and average $105 \mu \mathrm{m}$ particle size [21]. The PU resin is twopart (A and B) Smooth-On Task $3^{\circledR}$ resin. This lowcost semirigid urethane casting resins can cure quickly to semirigid plastics. These plastics are easy-to-use (mix ratio is $1 \mathrm{~A}: 1 \mathrm{~B}$ by volume) and have low viscosities for minimal bubble entrapment. PU resin physical properties were given in Table I [22]. A liquid silicone rubber resin (MoldStar30 ${ }^{\circledR}$ ) was used as a viscoelastic additive, obtained by mixing two supplied components (A and B) which are mixed $1 \mathrm{~A}: 1 \mathrm{~B}$ by volume. This easy to use platinum cured silicone features relatively low viscosities (according to ASTM D2393/12500 cps) and vacuum degassing is not required for most applications. The pot life is $45 \mathrm{~min}$ and cure time is $6 \mathrm{~h}$ at room temperature. MoldStar30 ${ }^{\circledR}$ has 30 Shore A hardness. Tensile strength (ASTM D412) is $2.90 \mathrm{MPa}$ and elasticity modulus is 0.66 MPa [23]. Close-cell structure was obtained after incorporation of GBs.

The syntactic foams were produced by carefully mixing PU resin, silicone rubber, and GBs by hand. After mixing for $20 \mathrm{~min}$, the mixture was filled into wax molds. 


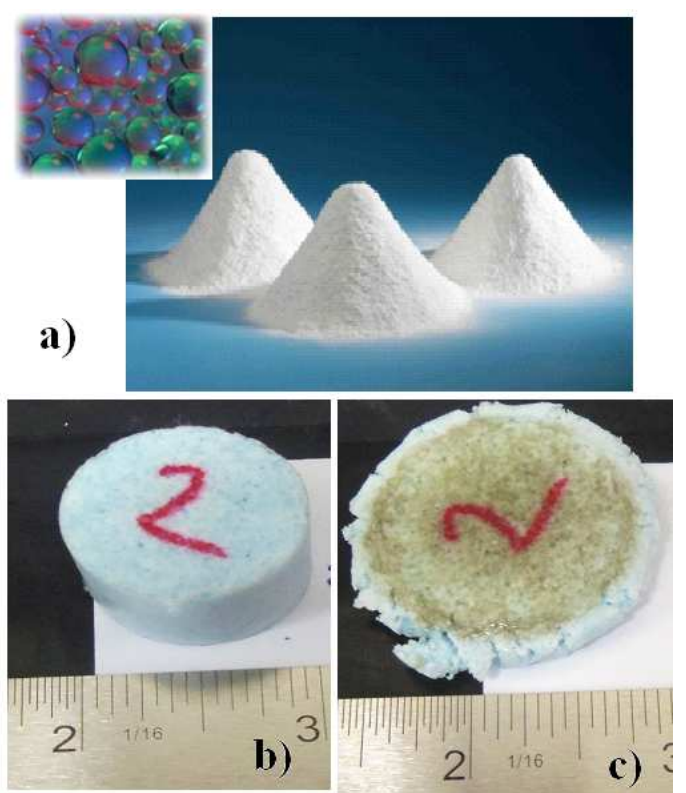

Fig. 1. (a) Glass bubbles A20/1000 [21], (b) quasistatic compression specimen syntactic foam type A (c) postmortem picture of the quasi-static compressed specimen.

The specimen was designed to be cylindrical with a diameter of $25 \mathrm{~mm}$ and a height of $17 \mathrm{~mm}$ for quasi-static compression experiments (Fig. 1b). Specimens for high strain rate experiments were cylindrical with a diameter $8.5 \mathrm{~mm}$ and $4 \mathrm{~mm}$ height. Three different type of syntactic foams were produced by mixing different weight percentages of GBs with PU resin. All produced matrix and syntactic foam mixtures contain constant $10 \%$ weight percentage of silicone rubber.

TABLE I

Polyurethane casting resin physical properties [22].

\begin{tabular}{c|c}
\hline \hline Pot life [min] [23 ${ }^{\circ} \mathrm{C}$ ] (ASTM D2471) & 20 \\
Cure time [min] [23 ${ }^{\circ} \mathrm{C}$ ] & 90 \\
Tensile strength [MPa] (ASTM D-638) & 45.85 \\
Tensile modulus [GPa] (ASTM D-638) & 2 \\
Elongation at break [\%] (ASTM D-638) & 6 \\
Flexural strength [MPa] (ASTM D-790) & 65.5 \\
Flexural modulus [MPa] (ASTM D-790) & 1986 \\
Compressive strength [MPa] (ASTM D-695) & 57.2 \\
Compressive modulus [MPa] (ASTM D-695) & 538 \\
Shrinkage in/in (ASTM D2566) & 0.0025 \\
Density [g/cm ${ }^{3}$ ] (ASTM D-1475) & 1.12 \\
Hardness (shore D) & 80 \\
Viscosity [cps] (ASTM D-2393) & 150
\end{tabular}

The studied materials can be described as below: matrix: silicone rubber mixed $\mathrm{PU}$ resin, syntactic foam type A: 10\% GB incorporated into matrix, syntactic foam type B: $30 \%$ GB incorporated into matrix, syntactic foam type C: $50 \%$ GB incorporated into matrix.
The density of the foam was obtained by weighing a specimen on a weight scale and calculating the volume based on the specimen geometry. The weight scale had an instrument sensitivity of $0.0001 \mathrm{~g}$. Quasi-static compression specimens were tested by using an Instron Universal 5585 tension/compression test machine at $1 \mathrm{~mm} / \mathrm{min}$ crosshead speed. High strain rate properties were obtained by using split Hopkinson pressure bar (SHPB) experimental setup (Fig. 2) [24]. All experiments were performed at room temperature. The microstructures of the specimens were investigated using scanning electron microscopy (SEM) images.

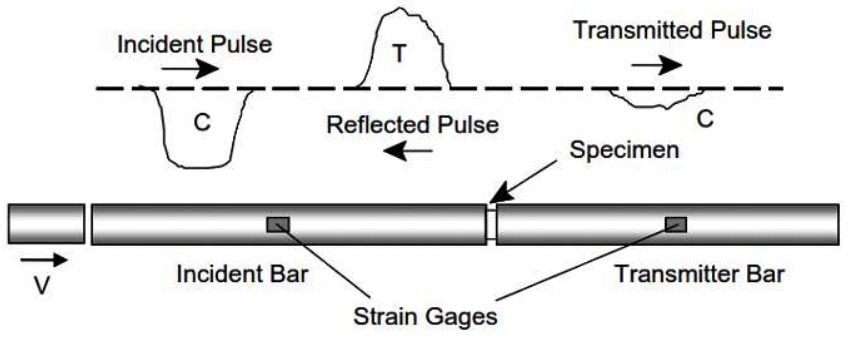

Fig. 2. Schematic illustration of the used SHPB [24].

\section{Results and discussion}

Developed syntactic foam densities decreased with the addition of GBs. In the syntactic foam type B, containing 30\% GBs by weight, the density decreased by $77.5 \%$. The quasi-static compression experiments were performed on the syntactic foams to obtain influence of GBs amount on compression strength and energy absorbing capabilities. The selected GBs have a low failure compression strength $(6.90 \mathrm{MPa})$ [21]. They collapse during the syntactic foam compression. Because of this, the foams' stress versus strain plots shows more plateau regions, suggesting greater energy absorbing properties (Fig. 1c).

The variations of the quasi-static compression behavior are given in Fig. 2 for the syntactic foams. It can be observed in Fig. 2 that the quasi-static compression yield strengths were reduced by incorporating the GBs into the PU resin based matrix. However, plateau regions were extended due to collapsing GBs inside the produced syntactic foams. Moreover, elastomeric silicone rubber addition also decreased the yield strength of the PU, but it availed more extension performance.

The comparative results were given in Table II.

Figure 3 shows experimental results of quasi-static and high strain rate compression loaded specimens. The quasi-static compression stress-strain behaviors of the produced syntactic foams were given in Fig. 3a. In this figure, the matrix material shows higher compression strength than the PU based syntactic foams. It is an expected result because GB incorporation produces empty cells inside the matrix. These empty cells reduce the strength of the composite, cause matrix weakness and stress concentrations. The high strain rate 
TABLE II

Quasi-static compression experimental results of the developed foams.

\begin{tabular}{c|c|c|c|c}
\hline \hline Materials & $\begin{array}{c}\text { Density } \\
{\left[\mathrm{kg} / \mathrm{m}^{3}\right]}\end{array}$ & $\begin{array}{c}\text { Comp. yield } \\
\text { strength } \\
{[\mathrm{MPa}]}\end{array}$ & $\begin{array}{c}\text { Comp. } \\
\text { mod. } \\
{[\mathrm{MPa}]}\end{array}$ & $\begin{array}{c}\text { Elongation } \\
{[\%]}\end{array}$ \\
\hline matrix & 952 & 40 & 696 & 65 \\
$\begin{array}{c}\text { syntactic foam } \\
\text { type A }\end{array}$ & 444.28 & 11.7 & 454 & 73 \\
$\begin{array}{c}\text { syntactic foam } \\
\text { type B }\end{array}$ & 252 & 8.5 & 553 & 76 \\
$\begin{array}{c}\text { syntactic foam } \\
\text { type C }\end{array}$ & 376 & 7.5 & 206.94 & 77 \\
polyurea [20] & 1000 & 5.38 & 8.9 & 61.9
\end{tabular}

compression experimental results were given in Fig. 3b. The high strain rate experiments were performed to understand strain rate sensitivity of the developed foams. The true stress-true strain behaviors of syntactic foam type B (30\% GB incorporated into the matrix) and matrix materials can be seen in this figure. Although the GB incorporation into the matrix reduced the yield stress in the quasi-static compression loading case, the yield stress increased by GB incorporation into the matrix in the high strain rate loading case. By comparing both figures (Fig. 3a and b), it can be said that the developed syntactic foam materials showed very high strain rate sensitivity and yield strengths increased almost eight times by GB incorporation into the matrix. These results can be explained by GBs fractures and collapsing cells. This fracture triggered the deformation mechanisms in the developed syntactic foams.

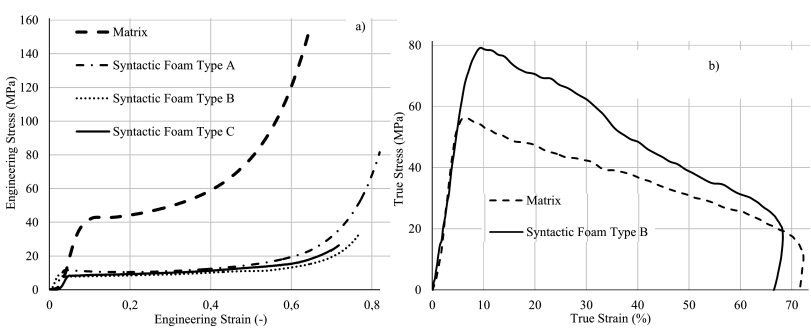

Fig. 3. Experimental results: (a) quasi-static compression experiments, (b) split Hopkinson pressure bar compression experiments.

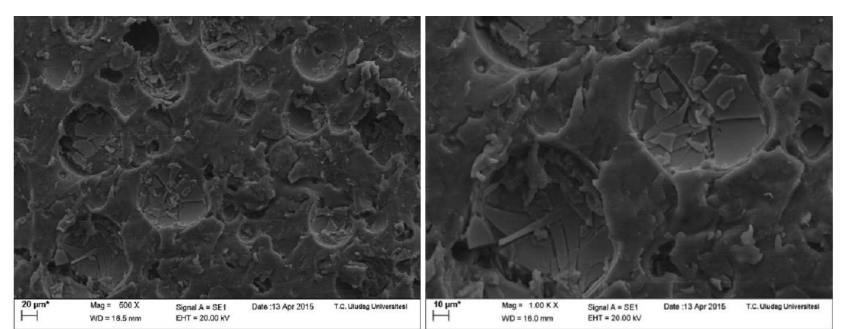

Fig. 4. Fracture surfaces of syntactic foam type B specimen at strain rate $28001 / \mathrm{s}$ : (a) $500 \times$, (b) $1000 \times$.
In Fig. 4, the postmortem SEM images were shown after $28001 / \mathrm{s}$ strain rate compression experiment subjected to the syntactic foam type B specimens. The figures demonstrate the fracture of the GBs and failure of the material at different magnifications.

\section{Conclusions}

In this study, a novel syntactic foam by incorporation of GBs into PU resin with elastomeric silicone rubber toughening were developed. Developed materials were shown as very high strain rate sensitive compression properties. Obtained results can be summarized below:

1. The PU syntactic foams display a particular strain rate sensitivity superior to that of silicone rubber toughened rigid PU and the polyurea impact resistive covers, indicating that the embedded glass micro balloons trigger the deformation mechanisms which enhance the response at high strain rate.

2. During compression tests, the plateau (crush) regions improved by introducing higher amounts of GBs. The fracture of GBs inside the matrix increased the energy absorption capability of the matrix. This GB fracture mechanism produces an empty deformable cell with broken GB wall pieces.

3. Developed syntactic foam type B material has eight times higher strength under high strain rates than quasi-static loading case.

\section{Acknowledgments}

The author would like to thank Dr. Arun Shukla for providing an opportunity to study in the DynamicPhotomechanics Laboratory (DPML)/University of Rhode Island, Dr. Sandeep Abotula for his help to perform SHPB experiments. The author also acknowledges the financial support provided by TUBITAK 2219 Int. Post Doc. Research Fellowship Program and 3M Ind. \& Transp. Business En. \& Adv. Mat. Div.

\section{References}

[1] V. Shabde, K. Hoo, G. Gladysz, J. Mater. Sci. 41, 4061 (2006).

[2] G. Gladysz, B. Perry, G. McEachen, J. Lula, J. Mater. Sci. 41, 4085 (2006).

[3] F.A. Shutov, Adv. Polym. Sci. 73/74, 63 (1986).

[4] H.H. Kim, H.H. Oh J. Appl. Polym. Sci. 76, 1324 (2000).

[5] L.H. Smiley, Mater. Eng. 103, 27 (1986).

[6] V.T. Phan, D. Choqueuse, J.Y. Cognard, L. Sohier, Prog. Org. Coat. 76, 341 (2013).

[7] C.I. Stuckey, T.R. Reinarts, D. Davis, AIP Conf. Proc. 552, 298 (2001).

[8] F. Grosjean, N. Bouchonneau, D. Choqueuse, V. Sauvant-Moynot, J. Mater. Sci. 44, 1462 (2009). 
[9] N. Bouchonneau, V. Sauvant-Moynot, D. Choqueuse, F. Grosjean, E. Poncet, D. Perreux, J. Petrol. Sci. Eng. 73, 1 (2010).

[10] A. Corigliano, E. Rizzi, E. Papa, Compos. Sci. Technol. 60, 2169 (2000).

[11] L. Bardella, F. Genna, Int. J. Solids Struct. 38, 307 (2001)

[12] E.S. Weiser, T.F. Johnson, T.L.S. Clair, Y. Echigo H. Kaneshiro, High Perform Polym. 12, 1 (2000).

[13] A. Pellegrino, V.L. Tagarielli, R. Gerlach, N. Petrinic, Int. J. Impact Eng. 75, 214 (2015).

[14] V. Yakushin, L. Bel'kova, I. Sevastyanova, Mech. Comp. Mater. 48, 579 (2012).

[15] D.U. Shah, F. Vollrath, D. Porter, Polymer 56, 93 (2015).

[16] J. Shim, G. Mohr, Int. J. Impact Eng. 36, 1116 (2009).
[17] K. Ackland, C. Anderson, T.D. Ngo, Int. J. Of Impact Eng 51, 13 (2013).

[18] Y.A. Bahei-El-Din, G.J. Dvorak, O.J. Fredricksen, Int. J. Solid Struct 43, 7644 (2006).

[19] L. Xue, W. Mock Jr., T. Belytschko Mech. Mater. 42, 981 (2010).

[20] N.Gardner, E. Wang, P. Kumar, A. Shukla, Exp. Mech. 52, 119 (2012).

[21] www.3M.com/oilandgas.

[22] www.smooth-on.com/tb/files/TASK_2_3_TB.pdf.

[23] www.smooth-on.com/Silicone-Rubber-an/c2/ index.html.

[24] S.A. Tekalur, A. Shukla, K. Shivakumar, Compo Struct 84, 271 (2008). 